\title{
Tension pneumoperitoneum following EBUS
}

\author{
Aldo Cristalli, ${ }^{1}$ Valentina Melis, ${ }^{1}$ Stefania Colombo, ${ }^{1}$ Lorenzo Dioscoridi (i) ${ }^{2}$
}

\begin{abstract}
'Servizio Anestesia e Rianimazione, Ospedale Niguarda Ca' Granda, Milan, Italy

${ }^{2}$ Digestive Endoscopy Unit, Azienda Socio Sanitaria Territoriale Grande Ospedale Metropolitano Niguarda, Milano, Italy
\end{abstract}

Correspondence to Dr Lorenzo Dioscoridi; dioscoridi.lorenzo@virgilio.it

Accepted 21 May 2020

\section{DESCRIPTION}

A 78-year-old man underwent endobronchialultrasound (EBUS) transbronchial needle aspiration (TBNA) for suspect neoplastic peribronchial adenopathy. His medical history included mitral valve annuloplasty complicated by atrial flutter episode treated by electric cardioversion, anaemia and hypothyroidism.

The procedure was performed in supine position and deep sedation using propofol intravenous through target continuous infusion (infusion rate: $3.5 \mu \mathrm{g} / \mathrm{mL}$; total amount: $380 \mathrm{mg}$ ). Vital parameters measured before the procedure were normal.

The procedure was interrupted three times because of repeated episodes of desaturation. Vigorous ventilation through a facial mask was needed to return to normal $\mathrm{SaO}_{2}$ values.

Shortly after the procedure, arterial pressure fell to $80 / 50 \mathrm{~mm} \mathrm{Hg}$ and FC (heart rate) increased to $120 /$ min. Respiratory rate climbed up to 33 acts/ min. Norepinephrine infusion was started at $0.05-$ $0.1 \mu \mathrm{g} / \mathrm{kg} / \mathrm{min}$. Urgent abdominal CT scan reported an acute tension pneumoperitoneum (TP) (figures 1 and 2) responsible for the sudden clinical impairment as suspected clinically before. No pneumomediastinum neither pneumopericardium were detected. Peroral intraluminal contrast medium showed no leaks. Fluid collections were not seen. A Veress needle was placed to ease the abdominal tension. The patient was then admitted to the intensive care unit for further observation with normal circulatory parameters and was extubated on the following day. On the fourth postprocedural day, he was dismissed from the hospital in good general conditions.

As intrathoracic causes of pneumoperitoneum, Macklin ${ }^{1}$ demonstrated that air, following excessive alveolar distention, could migrate from the ruptured alveoli along the perivascular sheats towards the

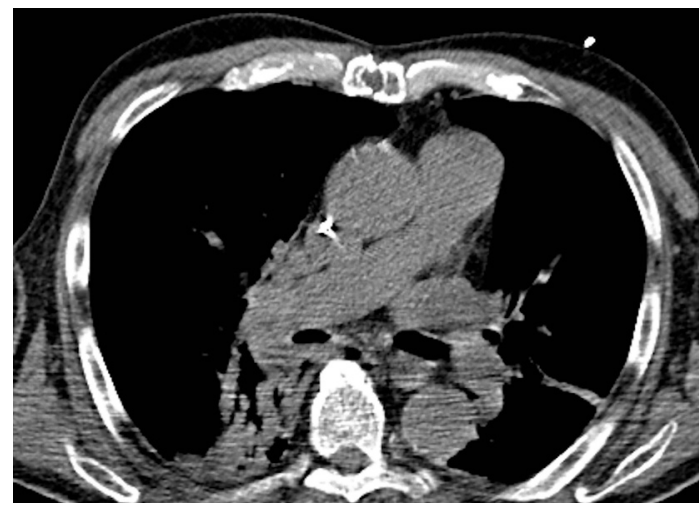

Figure 1 Chest CT scan in tension pneumoperitoneum reporting no pneumomediastinum.

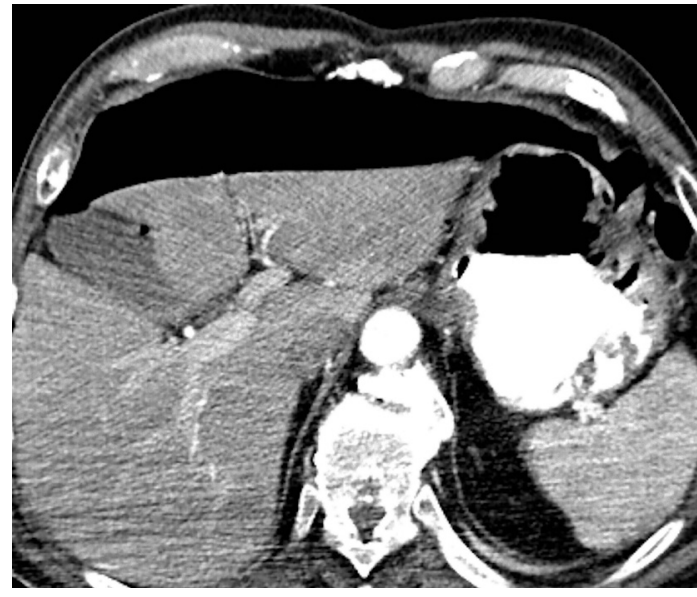

Figure 2 Intraluminal contrast medium at the CT scan showed no leaks neither perforations in tension pneumoperitoneum after endobronchial-ultrasound.

mediastinum and produces pneumomediastinum and subcutaneous emphysema as well as pneumoretroperitoneum and subsequently pneumoperitoneum. Another possible explanation might be the passage of air through microperforations of the diaphragm in the parasternal and posterolateral regions causing a pneumo-retroperitoneum. From there, it can rupture into the intraperitoneal cavity.

TP is a rather rare adverse event with possible severe impact on respiratory and circulatory system and must be treated accordingly.

It may be responsible for circulatory collapse due to pooling of the blood in the abdomen, thus causing a severe reduction of blood flow from the inferior vena cava to the heart and a dramatic fall of preload. Consequently, there is a reduction of cardiac output which becomes clinically evident with increased heart rate and low blood pressure. Increasing respiratory insufficiency due to elevation of both haemidiaphragms and reduced diaphragmatic excursion may become manifest with a decrease in oxygen haemoglobin saturation, a high inspired oxygen fraction notwithstanding. If TP gets worse, the patient may suffer respiratory and cardiac arrest.

The causes of TP may still be difficult to find. According to literature, there is only another case report which described a TP following EBUS-TBNA. $^{2}$

In both cases emergency decompression had to be performed. Air could have filled the stomach and could have migrated in the bowel while relieving the respiratory insufficiency.

Excessive ventilation due to important desaturation could be responsible for the iatrogenic component, followed by passage of air from the bowel to 
peritoneal space through gastric and/or bowel microperforations which remained undetected by intraluminal contrast CT scan.

Since our case is the second report in the whole literature in a short time, it could be advisable to keep an alert mind on such adverse events. ${ }^{3}$

In absence of bowel perforation, decompression remains the therapy of choice and must be promptly performed.

\section{Learning points}

- Tension pneumoperitoneum is a rare but considerable adverse event during endobronchial-ultrasound.

- Immediate abdominal decompression avoids the worst consequences of tension pneumoperitoneum.

- Remind abdominal adverse events also during chest procedures.
Contributors $\mathrm{AC}$ and VM reported the case and wrote the paper. SC prepared the images. LD revised the manuscript.

Funding The authors have not declared a specific grant for this research from any funding agency in the public, commercial or not-for-profit sectors.

Competing interests None declared.

Patient consent for publication Obtained.

Provenance and peer review Not commissioned; externally peer reviewed.

\section{ORCID iD}

Lorenzo Dioscoridi http://orcid.org/0000-0003-4975-018X

\section{REFERENCES}

1 Macklin CC. Transport of air along sheaths of pulmonic blood vessels from alveoli to mediastinum. Arch Intern Med 1939:64:913-26.

2 Muriana P, Carretta A, Ciriaco P, et al. Isolated tension pneumoperitoneum following endobronchial ultrasound-guided transbronchial needle aspiration complicated by cardiac peri-arrest: a case report. Monaldi Arch Chest Dis 2018;88:999.

3 Nikolaev IS, Zamir D, Weiler Z. Pneumoperitoneum complicating bronchoscopy. Isr Med Assoc J 2003;5:131-2.

Copyright 2020 BMJ Publishing Group. All rights reserved. For permission to reuse any of this content visit

https://www.bmj.com/company/products-services/rights-and-licensing/permissions/

BMJ Case Report Fellows may re-use this article for personal use and teaching without any further permission.

Become a Fellow of BMJ Case Reports today and you can:

Submit as many cases as you like

- Enjoy fast sympathetic peer review and rapid publication of accepted articles

- Access all the published articles

Re-use any of the published material for personal use and teaching without further permission

\section{Customer Service}

If you have any further queries about your subscription, please contact our customer services team on +44 (0) 2071111105 or via email at support@bmj.com.

Visit casereports.bmj.com for more articles like this and to become a Fellow 